\title{
Biochemical markers as diagnostic/prognostic indicators for ischemic disease
}

\author{
Alkireidmi MA ${ }^{1,3}$, Al-Abbasi FA ${ }^{1}$, Mehanna $\mathrm{MG}^{1}$, Said S Moselhy ${ }^{1,2}$
}

1. Department of Biochemistry, Faculty of science, King Abdulaziz University, Jeddah, Saudi Arabia.

2. Department of Biochemistry, Faculty of science, Ain Shams University, Cairo, Egypt.

3. King Saud bin Abdul Aziz university for health sciences, college of science and health professions, Basic science department. Jeddah, Saudi Arabia.

\begin{abstract}
Objective: The use of a biomarker was extremely useful in clinical emergencies such as stroke to aid in triage and early management of cases. The diagnostic accuracy of laboratory biomarkers is run to approve the identification of easy, cheap and fast tests associated with cerebral ischemia and intracranial hemorrhage. The present study was designed to screen serum enolase activity, activities of CK-BB, LDH and lipid profile in patients with ischemic or related diseases as good diagnostic/prognostic indicator for ischemic diseases.

Methods: Sixty male subjects in the age range of ( $45 \pm 2$ years) were divided into four groups each with 15 participants: Group (I) normal . Group (II) patients recently diagnosed as ischemic disease; Group (III) hypertensive patients and Group (IV); diabetic patients enolase activity $(\mathrm{p}<0.001)$ and CK-BB $(\mathrm{p}<0.01)$ in ischemic and hypertensive patients compared with control and diabetic groups. LDH level was significantly elevated in ischemic, hypertensive and diabetic patients compared with controls $(p<0.001)$. The cut -off value for serum enolase was $62.5 \mathrm{nmol} / 1$ showing $90 \%$ sensitivity and $93 \%$ specificity for differentiation of ischemic disease. Positive correlations were observed between serum enolase $(\mathrm{r}=0.56)$, and CK-BB $(\mathrm{r}=0.53)$.

Conclusion: Serum enolase can be considered as a more sensitive and specific marker and used as a sensitive diagnostic or prognostic marker for ischemic related diseases.

Keywords: Serum enolase, ischemia, hypertension, diagnosis, prognostic.

DOI: https://dx.doi.org/10.4314/ahs.v18i2.13

Cite as: Alkireidmi MA, Al-Abbasi FA, Mehanna MG, Moselhy SS. Biochemical markers as diagnostic/prognostic indicators for ischemic disease. Afri Health Sci. 2018;18(2): 287-294. https://dx.doi.org/10.4314/abs.v18i2.13
\end{abstract}

\section{Introduction}

Transient ischemic attacks (TIA) are episodes in which a person has signs or symptoms of a stroke (e.g. numbness; inability to speak) that last for a short time ${ }^{1}$, but without any sign of stroke on brain scans such as MRI or CT. Symptoms of a TIA usually last between a few minutes and a few hours. A person may have one or many TIAs. People recover completely from the symptoms of a TIA. TIA is a warning sign that a person is at high risk for a stroke; immediate treatment can decrease or eliminate this risk ${ }^{2}$.

\section{Corresponding author: \\ Said S Moselhy, \\ Biochemistry Department, \\ Faculty of Science, king Abdulaziz University. \\ Tel: 00966566991424. \\ Email; moselhy6@hotmail.com}

Enolase is a glycolytic enzyme that catalyzes the conversion of 2-phosphoglycerate to phosphoenolpyruvate ${ }^{3}$. Enolase exists in the form of several tissue-specific isoenzymes, consisting of homo or heterodimers of 3 different monomer-isoforms (alpha, beta, and gamma) ${ }^{4}$. Neuron specific enolase (NSE) is a $78 \mathrm{kD}$ gamma-homodimer and represents the dominant enolase-isoenzyme found in neuronal and neuroendocrine tissues ${ }^{5}$. Its levels in other tissues, except erythrocytes, are negligible. The biological half-life of NSE in body fluids is approximately 24 hours. Due to this organ-specificity, concentrations of NSE in serum or, more commonly, cerebrospinal fluid (CSF), are often elevated in diseases which result in relative rapid (hours/days to weeks, rather than months to years) neuronal destruction. Measurement of NSE in serum of CSF can therefore assist in the differential diagnosis of a variety of neuron-destructive and neuro-degenerative disorders. The most common application is in the differential diagnosis of dementias, where elevated CSF con-

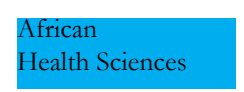

(C) 2018 Alkireidmi et al. Licensee African Health Sciences. This is an Open Access article distributed under the terms of the Creative commons Attribution License (https://creativecommons.org/licenses/by/4.0), which permits unrestricted use, distribution, and reproduction in any medium, provided the original work is properly cited. 
centrations support the diagnosis of rapidly progressive dementias. NSE might also have utility as a prognostic marker in neuronal injury ${ }^{6}$.

The evaluation of Neuron specific enolase level in serum and cerebrospinal fluid following cerebral ischemia provides a reliable bio-indicator of the degree of brain cell damage, and may allow for early prediction of outcome $^{7}$. In case of stroke, the first enolase peak within $7-18 \mathrm{~h}$ is found following admission and may reflect the initial damage to neuronal tissue, while a second elevation between days 1-3, may be related to edema and an increase in intracranial pressure ${ }^{8-10}$. For that, enolase can be used as a reflection of neuronal damage. In this study we aimed to find the correlation between serum enolase, $\mathrm{LDH}, \mathrm{CK}-\mathrm{BB}$ levels in patients with ischemia, hypertension and diabetes. This is promising as a good indicator to avoid ischemic disease and tissue damage.

\section{Subjects and methods}

This study was approved by the ethics committee of the King Abdul-Aziz University Hospital. A written informed consent was obtained from all participants prior to enrollment into the study. Sixty adult males volunteers were included in the present study, age ranging between 40-55 years. The subjects were divided into four groups each with 15: Group (I) normal subjects not suffering from any systemic diseases; Group (II) including patients recently diagnosed as ischemic disease; Group (III) including hypertensive patients $(\mathrm{BP} \geq 140 / 90)$ and Group (IV) including patients with type II diabetes, fasting $\mathrm{HAB} 1 \mathrm{C}>10 \%$.

Inclusion criteria were: chronic fatigue, diabetes, heart condition, hypertensive and stroke. Exclusion criteria were: Hormone replacement therapy, multiples sclero- sis, oral inflammation, advanced periodontitis and severe gingivitis. Five $\mathrm{ml}$ blood samples were collected from all subjects following an overnight 12 hours fasting. Immediately following collection, samples were centrifuged at $8000 \mathrm{rpm}$ at $-4^{\circ} \mathrm{C}$ for separation of serum.

\section{Biochemical assays}

Lipid profile, total cholesterol, LDL-c, HDL-c, enolase activity, Lactate LDH and CK-BB were measured in serum samples using available kits from BIOLINE (England).

\section{Statistical analysis}

Statistical analysis was performed using the SPSS package [version 20]. Results were expressed as mean \pm SD. A p value $\leq 0.05$ was considered significant. Using analysis of variance (ANOVA), there was a high significance between the groups when comparing sample.

\section{Results}

Results obtained in figure 1 show that, there was a significant elevation in the level of serum total cholesterol in ischemic, hypertensive and diabetic groups compared with the control group ( $\mathrm{p}<0.001,<0.01$ and $<0.05)$ respectively. The elevation in hypertension was more than in diabetes. Serum HDL-c level was significantly lower in ischemic, hypertension and diabetic groups compared with the normal group $(\mathrm{p}<0.001,<0.01$ and $<0.05)$ respectively. Serum LDL-c level was significantly increased in ischemic, hypertension and diabetic compared with the control group ( $p<0.001,<0.01$ and $<0.05)$ respectively. While there was no significant difference in the level of LDL-c between the ischemic, hypertension and the diabetic groups. 


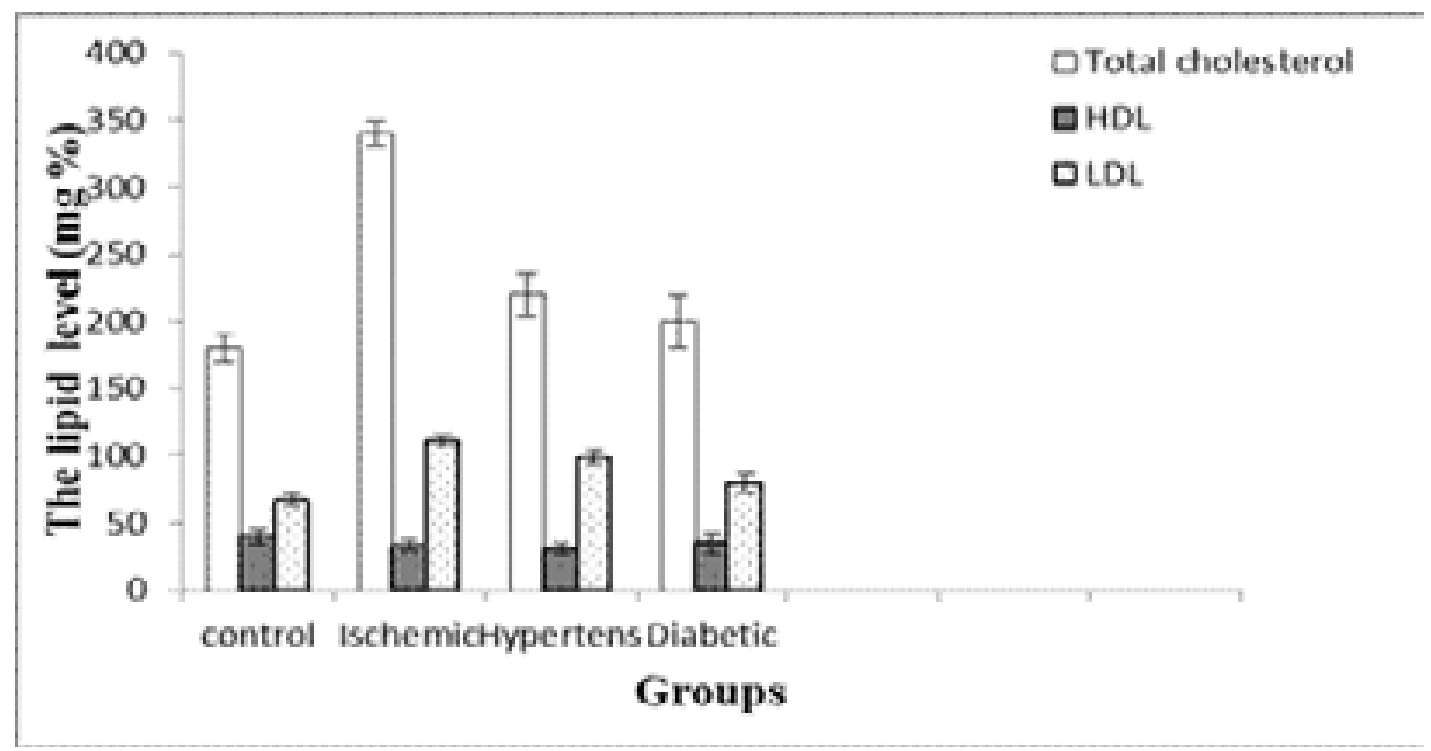

Fig. (1): Serum TC, LDL-c and HDL-c levels in the different groups (Mean \pm SD).

Figure 2 shows that, Serum lactate dehydrogenase activity was significantly increased $(p<0.001)$ in both ischemic , hypertension and diabetic groups compared with the control group while serum creatine kinase (CK-BB) showed a higher values in both hypertension and diabetic groups compared to control and stroke groups $(p<0.001$ and $<0.001$ ). However it was highest in the hypertension, ( $p$ $<0.001)$ and slightly increased in the diabetic group compared with the control group $(\mathrm{p}<0.05)$ Figure 3.

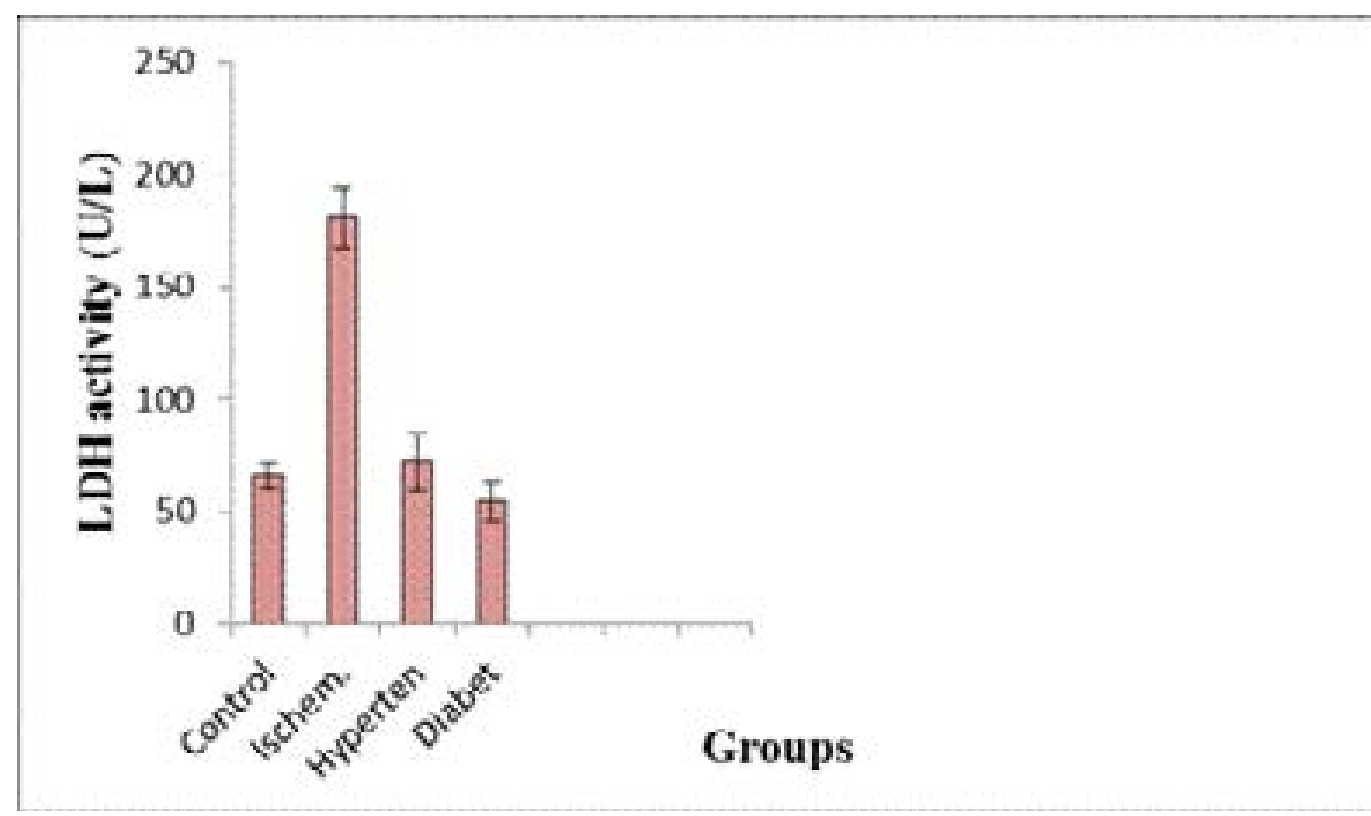

Fig. (2): Serum LDH activity in the different groups (Mean \pm SD). 


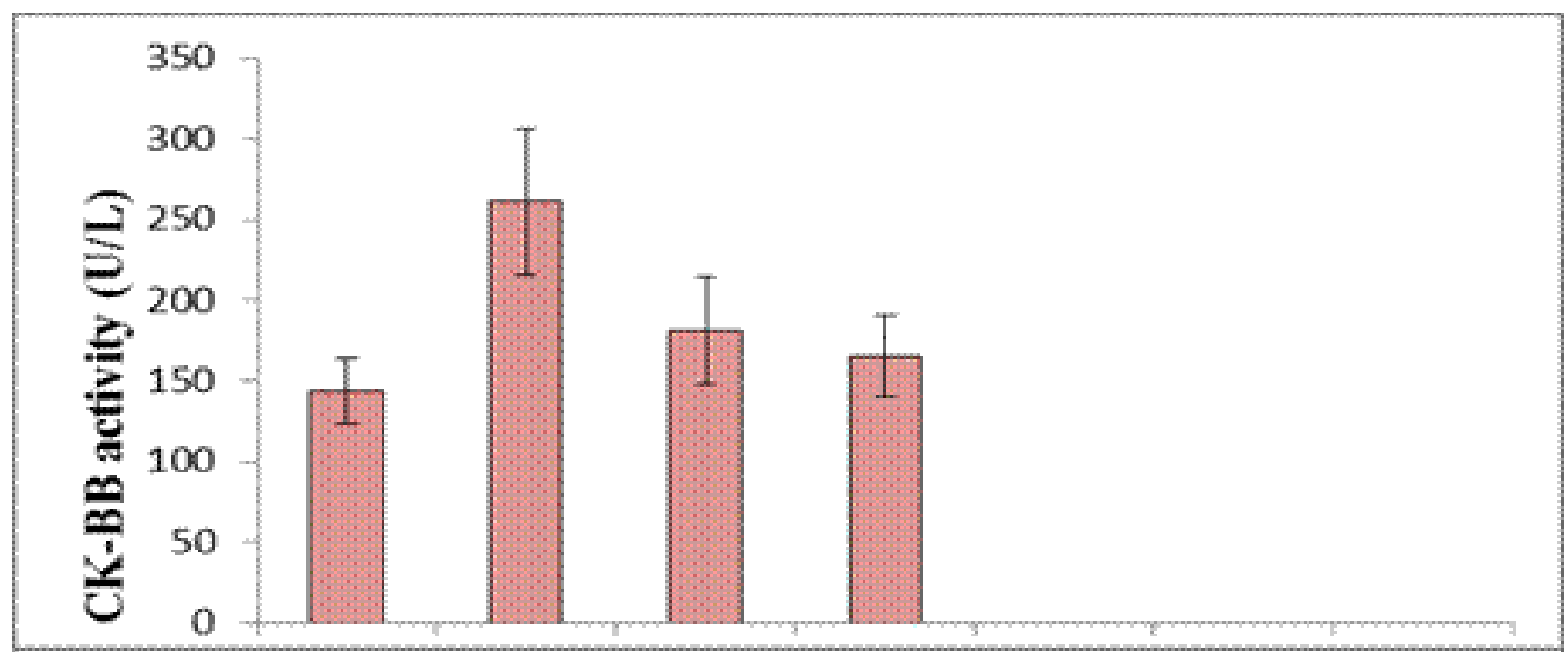

Control Ischemic Hypertension Diabetic

\section{Groups}

Fig. (3): Serum CK activity in the different male rat groups (Mean $\pm \mathrm{SD}$ ).

Figure 4 reveals that, Serum enolase activity was significantly highest in the hypertension, ischemic $(\mathrm{p}<0.001$, $<0.001)$ and slightly increased in the diabetic group compared with the control group ( $p<0.05)$, however the ischemic elevation was similar to the hypertension group and in diabetics, it was lower. Receiver operating curve (ROC) analysis for serum enolase in different groups showing an AUC of 0.92 with a cutoff value of $10 \%$ (sensitivity,
95.5\%; specificity, 97\%). It was increased about 8 folds in ischemic and hypertension group as compared with the control and diabetic groups. However, it was elevated about 5 folds in diabetic group compared to the control group. The cut-off value in $92 \%$ ischemic patients was $80 \mathrm{U} / \mathrm{L}, 80 \%$ of hypertensive patients. Positive correlations were observed between serum enolase and CK-BB $(r=0.53)$ while were not correlated with other laboratory markers such as plasma LDH and lipid profile.

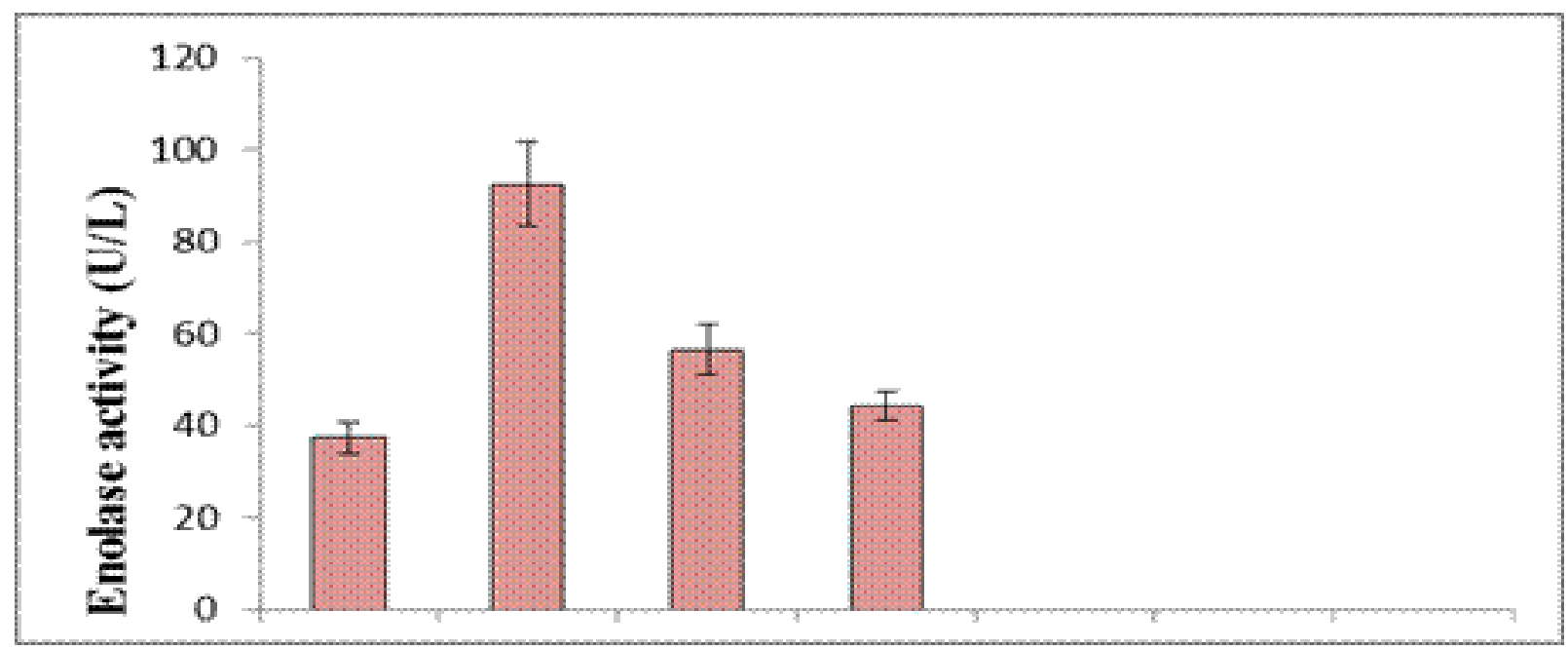

Control schemic Hypertension Diabetic

Subjects groups

Fig. (4): Serum enolase activity in the different groups (Mean $\pm S D$ ). 


\section{ROC Curve}

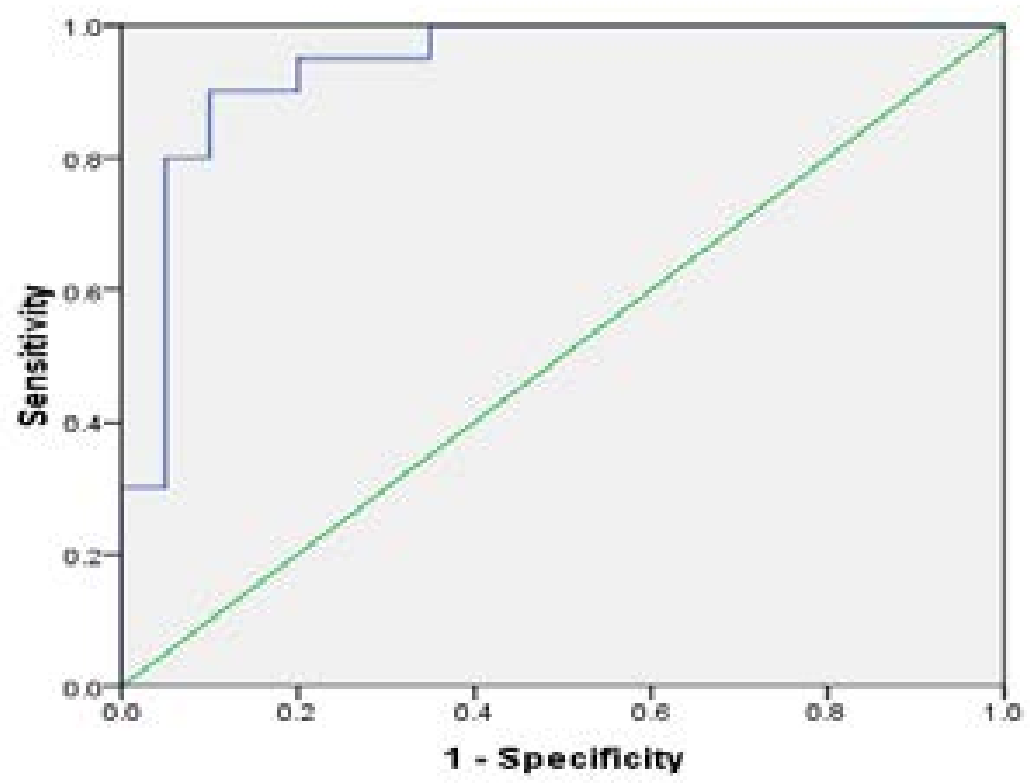

Fig 5: The ROC curve of Ischemic versus control

ROC Curve

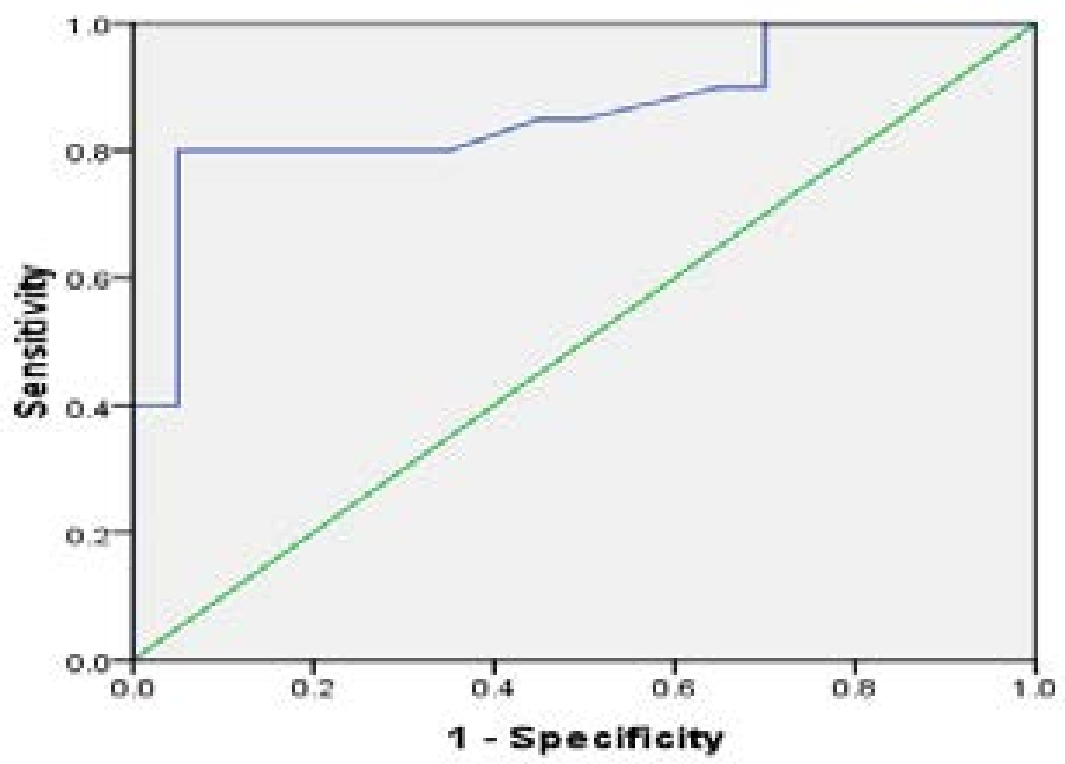

Diagonal segments are produced by ties.

Fig 6: The ROC curve of Hypertension versus Control 


\section{Discussion}

The blood-brain barrier is compromised in patients with stroke. Neuron-specific markers, such as neuron specific enolase (NSE) in the circulation may allow the pathophysiology and prognosis of patients with cerebrovascular diseases to be evaluated ${ }^{11-16}$. The present study was designed to measure NSE in serum of patients with ischemic stroke and patients with related diseases as a diagnostic tool for early prediction of ischemic stroke. The diagnostic accuracy of laboratory biomarkers is run to approve the identification of easy, cheap and fast test associated with cerebral ischemia and intracranial hemorrhage.

In the present study, results revealed that there was a significant increase in the level of serum total cholesterol in ischemic, hypertension and diabetic groups compared with the control group. However, a significant increase of serum LDL-c in the ischemic, hypertension and diabetic groups compared with the normal group. Weak positive correlations between saliva and serum cholesterol HDL-c was found. Salivary and serum HDL-c concentration recorded in this study may reflect the protective function of HDL-c, since it was markedly reduced in patients with stroke as well as patients with stroke- related diseases. This is in accordance with a study that stated a significant elevation of LDL and a significant decrease in HDL in hypertensive and diabetic patients as compared to controls ${ }^{17-20}$. There are several possible mechanisms by which serum lipids can reach saliva. Within the salivary glands, transfer mechanisms include intracellular and extracellular routes ${ }^{21,22}$. Results obtained indicated that a significant elevation in the levels of total $\mathrm{LDH}$ and $\mathrm{CK}-\mathrm{BB}$ in serum of ischemic, hypertensive and diabetes versus controls. It was concluded that, the elevation of serum enolase level may be implicated as a predisposition for incidence of hypertension and diabetes and increases the risk of stroke ${ }^{23-25}$. The measurement of NSE concentrations in serum and cerebrospinal fluid (CSF) following cerebral ischemia and traumatic head injury provides a reliable laboratory indicator of the degree of brain cell damage, may allow for early prediction of outcome and may reflect the damage to neuronal tissue. Therefore, NSE concentrations can provide early information about neuronal damage.
The present study was designed to measure NSE in serum as early diagnosed in patients with stroke and patients with stroke-related diseases.

However, the concentrations of serum NSE in hypertensive and diabetic patients were significantly increased. This indicated that diabetic patients showed some sort of neuronal damage and/or blood-brain barrier disruption. This finding was in agreement with ${ }^{26}$ who demonstrated a significant increase in antibodies against NSE in both type 1 and type 2 diabetic subjects compared to healthy controls. In hypertensive patients and patients with ischemic heart disease, the mean serum NSE ranked an intermediate value between ischemic stroke and healthy controls.

The presence of NSE in saliva of patients with stroke and 'at risk' patients may be explained by the fact that the integrity of the blood-brain barrier is disrupted to various degrees in these patients, and leakage of this enzyme outside the CNS can be detected in salivary secretion. Recently, the determination of SE has been described as a sensitive and easy-to-perform marker for the diagnosis of ischemic for early prediction of occurrence

Positive correlations were observed between serum enolase $(r=0.56)$, and CK-BB $(r=0.53)$.

\section{Conclusion}

Serum enolase can be considered as a more sensitive and specific marker and used as a sensitive diagnostic or prognostic marker for ischemic related diseases.

\section{Competing interest}

The authors certify that there is no actual or potential conflict of interest in relation to this article.

\section{Acknowledgment}

This project was funded by the king Abdulaziz city for science and technology (KACST) under grant no. ( AT35-207).

\section{References}

1. Champe PC, RA Harvey, DR Ferrier. 2007. Diabetes Mellitus. In Lippincott's Illustrated Reviews: Biochemistry, Fourth Edition. K. Scogna, editor. Lippincott Williams \& Wilkins. 337-348. 
2. Chiappin SG, Antonelli R Gatti, EF De Palo. 2007. Saliva specimen: a new laboratory tool for diagnostic and basic investigation. Clinica chimica acta; International Journal of Clinical Chemistry. 383:30-40.

3. Chou CL, YJ Lin, HL Po, CK Chang. 2010. Subarachnoid hemorrhage--a rare complication after intravenous thrombolysis in an ischemic stroke patient. The American Journal of Emergency Medicine. 28:984 e981-983.

4. Clow AS Edwards, G Owen, G Evans, P Evans, F Hucklebridge, A Casey. 2006. Post-awakening cortisol secretion during basic military training. International journal of psychophysiology: Official Journal of the International Organization of Psychophysiology. 60:88-94.

5. Cockburn DM. 1983. Signs and symptoms of stroke and impending stroke in a series of optometric patients. American Journal of Optometry and Physiological Optics;60(9):749-53.

6. Fillee CG Vranken, M Othmane, M Philippe, JM Allaeys, A Courbe, JL Ruelle, R Peeters. 2011. Results of the recalibration of creatinine measurement with the modular Beckman Coulter Jaffe creatinine method. Clinical chemistry and laboratory medicine : CCLM / FESCC. 49:1987-1999.

7. Fleissig Y, O Deutsch, E Reichenberg, M Redlich, B Zaks, A Palmon, DJ Aframian. 2009. Different proteomic protein patterns in saliva of Sjogren's syndrome patients. Oral Diseases. 15:61-68.

8. Friedewald WTT, RI Levy, DS Fredrickson. 1972. Estimation of the concentration of low-density lipoprotein cholesterol in plasma, without use of the preparative ultracentrifuge. Clinical Chemistry. 18:499-502.

9. Goldstein DS. 1979. The electrocardiogram in stroke: relationship to pathophysiological type and comparison with prior tracings. Stroke; A Journal of Cerebral Circulation. 10:253-259.

10. Granger DA, EB Schwartz, A Booth, M Arentz. 1999. Salivary testosterone determination in studies of child health and development. Hormones and Behavior. 35:18-27. 11. Groschl M, R Wagner, M Rauh, HG. Dorr. 2001. Stability of salivary steroids: the influences of storage, food and dental care. Steroids. 66:737-741.

Hademenos GJ, TF Massoud. 1997. Biophysical mechanisms of stroke. Stroke; A Journal of Cerebral Circulation. 28:2067-2077.
12. Henson BS, DT Wong. 2010. Collection, storage, and processing of saliva samples for downstream molecular applications. Methods in Molecular Biology. 666:21-30.

Hovsepyan MR, MJ Haas, AS Boyajyan, AA Guevorkyan, AA Mamikonyan, SE Myers, AD Mooradian. 2004. Astrocytic and neuronal biochemical markers in the sera of subjects with diabetes mellitus. Neuroscience letters. 369:224-227.

13. Ivanovski K, V Naumovski, M Kostadinova, S Pesevska, K Drijanska, V Filipce. 2012. Xerostomia and salivary levels of glucose and urea in patients with diabetes. Prilozi; 33:219-229.

14. Jacobs N, NA Nicolson, C Derom, P Delespaul, J van Os, I Myin-Germeys. 2005. Electronic monitoring of salivary cortisol sampling compliance in daily life. Life Sciences. 76:2431-2443.

15. Karjalainen S, L Sewon, E Soderling, B Larsson, I Johansson, O Simell, H Lapinleimu, R Seppanen. 1997. Salivary cholesterol of healthy adults in relation to serum cholesterol concentration and oral health. Journal of Dental Research. 76:1637-1643.

16. Kisialiou A, R Grella, A Carrizzo, G Pelone, M Bartolo, C Zucchella, F Rozza, G Grillea, C Colonnese, L Formisano, M Lembo, AA Puca, C Vecchione. 2014. Risk factors and acute ischemic stroke subtypes. Journal of the Neurological Sciences. 339:41-46.

17. Kudielka BM, JE Broderick, C Kirschbaum. 2003. Compliance with saliva sampling protocols: electronic monitoring reveals invalid cortisol daytime profiles in noncompliant subjects. Psychosomatic Medicine. 65:313-319. 18. Latchaw RE, MJ Alberts, MH Lev, JJ Connors, RE Harbaugh, RT Higashida, R Hobson, CS Kidwell, WJ Koroshetz, V Mathews, P Villablanca, S Warach, B Walters. 2009. Recommendations for imaging of acute ischemic stroke: a scientific statement from the American Heart Association. Stroke; A Journal of Cerebral Circulation. 40:3646-3678.

19. Lawrence HP. 2002. Salivary markers of systemic disease: noninvasive diagnosis of disease andmonitoring of general health. J Can Dent Assoc. 68:170-174.

20. Lloyd CE, J Stephenson, JH Fuller, TJ Orchard. 1996. A comparison of renal disease across two continents; the epidemiology of diabetes complications study and the EURODIAB IDDM Complications Study. Diabetes care. 19:219-225. 
21. Maas MB, JE Safdieh. 2009. ischemic Stroke: Pathophysiology and Principles of localization. Neurology. 13. part I;1-2.

22. Mandel ID. 1989. The role of saliva in maintaining oral homeostasis. J Am Dent Assoc. 119:298-304.

Markus, H. 2004. Stroke: causes and clinical features. Medicine. 32:57-61.

23. Masserini B, V Morelli, S Bergamaschi, F Ermetici, C Eller-Vainicher, AM Barbieri, MA Maffini, A Scillitani, B Ambrosi, P Beck-Peccoz, I Chiodini. 2009. The limited role of midnight salivary cortisol levels in the diagnosis of subclinical hypercortisolism in patients with adrenal incidentaloma. European Journal of Endocrinology / European Federation of Endocrine Societies. 160:87-92.
24. McKeone BJ, JR Patsch, HJ Pownall. 1993. Plasma triglycerides determine low density lipoprotein composition, physical properties, and cell-specific binding in cultured cells. J Clin Invest. 91:1926-1933.

25. Montaner J, M Mendioroz, P Delgado, T Garcia-Berrocoso, D Giralt, C Merino, M Ribo, A Rosell, A Penalba, I Fernandez-Cadenas, F Romero, C Molina, J Alvarez-Sabin, M Hernandez-Guillamon. 2012. Differentiating ischemic from hemorrhagic stroke using plasma biomarkers: the S100B/RAGE pathway. J Proteomics. 75:4758-4765. 26. Zhang Y, J Tuomilehto, P Jousilahti, Y Wang, R Antikainen, G Hu. 2011. Lifestyle factors on the risks of ischemic and hemorrhagic stroke. Archives of Internal Medicine. 171:1811-1818. 